\title{
An Investigation into the Implementation of Call in Government Colleges of District Hyderabad: A Study on English Teachers' Perceptions
}

\author{
Ghulam Rasool Khan \\ MS Scholar \\ English Language Development Center, Mehran University, Jamshoro Sindh Pakistan \\ Miss Sadia Memon \\ Lecturer \\ English Language Development Center, Mehran University, Jamshoro Sindh Pakistan
}

\begin{abstract}
In the modern world technology has prevailed and now it is unstoppable to prevail more in the near future. As technology effected in every walk of life so does in education. Therefore, education is continuously transforming in all around the world through electronical resources and with the help of technological gadgets, tools, and other devices, the spread of has become easy enough that even lay men have some sort of comprehension to understand some English. Education is being flourished in well to do countries around the world by implementing computers in their education system. The technological or electronic based tool CALL known Computer Assisted Language Learning is not new in the world but in Pakistan to some extent it is. Even though many local researchers have already done much work dealing CALL and its aspects even then there is a huge vacuum to work on and make educational authorities aware about the end results of integrating technology if applied in our education system particularly in Higher Secondary Education. However, according to education policy 2017 by Ministry of Federal Education and Professional Training Government of Pakistan, it is required to include Information Communication Technology to meet the needs of variety of learners through information technology because the explosion of information is increasing a large scale therefore it is needed to get access of knowledge and make learning easy. Moreover, via increasing the access of technology the cost of education could come down and could meet the challenges of illiteracy and poverty. In this connection, the aim of the study is to investigate the perceptions of English teacher about the application and obstacles to the implementation of CALL and the related strategies which may be adopted to inculcate by inspecting the current capacity of the use of Computer Assisted Language Learning in the government colleges of Hyderabad Division. Concerning this, the study was conducted at government Boys and Girls colleges of Hyderabad by collecting data from English teachers through quantitative survey questionnaire. This research work finally analyzes that majority of the teachers are in favor to have change in education and implementing technology sure to be fruitful to bring out the potential of the students. This way learners will be well equipped to survive in the society positively and constructively.
\end{abstract}

Keywords:Computer, Perception, Implementation, Higher Secondary Education, Communication, Technology, Education system, Computer Assisted Language Learning (CALL).

DOI: $10.7176 /$ RHSS/11-8-05

Publication date: April $30^{\text {th }} 2021$

\section{Introduction}

Pakistan falls in the third world, therefore, yet she seriously needs a proper focus to develop the professional attitude on learning and teaching. According to the standard of education in Pakistan, all the major subjects are taught conventionally not using any technology in education however; technology has grown beyond the imagination. This advancement in the technology has impacted educating learners of all age groups around the world. To update the education system in Pakistan, there is a desperate need of not only theoretical but practical use of computer technology though, computer as subject is taught in higher education. Besides, in many countries around the world CALL has been in practiced as a tool in the field of teaching since 1960. In this connection, a lot of research work has been done in the world including Pakistan. In those studies, the benefits and limitations, attitudes and insights of students and teachers towards the use of CALL were focused in depths. Further, Warschauer's (1996) discovered in his studies that the involvement of CALL has affected the various educational institutions from school to university and home to offices. Likewise, the importance of positive and negative attitude plays a significant role in the introduction of learning and teaching through computer assisted language learning. Deciding the explanations behind these sorts of sentiments may be the initial phase but manageable one to adopt CALL. Comprehending students and teachers' perception of using CALL and influencing factors may help learners and facilitators to handle troubles in classroom. Brosnan (1995) moreover, 
the students of present time are in the mid of an explosion of academic information. With the latest computer technology, students can become more responsible for own learning. Therefore, teachers have to pay attention on their pedagogical regime. Irshad and Mamuna (2011) find in their study that there is a debate on the hypothesis of CALL benefits and related idea that the pedagogy of ESL in Pakistan in terms of infrastructure, computer hardware and software still there is an evolution.

\section{Statement of the Problem}

Among the researchers, a smaller number of scholars directly worked and inquired about the perceptions and attitudes of teachers while implementation of CALL for English language students (Kabata \& Wiebe, 2010; Kim, 2008). There is huge space between the perceptions of teachers and the attitudes of students for CALL. The output of most studies explored, Elaziz \& Mathews-Aydinli, 2010; Kabata \& Wiebe, 2010), the optimistic attitude of students using CALL in learning a language but a variable perception of teachers for using CALL in classroom for teaching language. As a result, the expectations of students of modern time do not meet with the integration of technology which teachers try to put in the context of English language learning and teaching. Taking into account the littleness of a strengthened subjected framework about reflections and experiences of teachers on CALL, the core target of this study is to discover the perceptions of the teachers in the regard of using CALL.

\section{Study's Aim}

The purpose of this work is to explore the barriers towards implementation of CALL at government colleges locating in district Hyderabad. Further, it is to specify the perception of teachers for using CALL in their teaching practice.

\section{Research Questions}

1. What is the current position of the use of CALL in Government colleges?

2. What are the perceptions of teachers of the strategies that should be adopted to include CALL in Government Colleges?

3. What are the perceptions of teachers concerning the main obstacles to the implementations of CALL in Government Colleges?

\section{Literature Review}

CALL is an approach which is immensely attractive to both language learners and teachers because it may be capable of giving suitable feedback and instruction to individual people to make learners correct on their computerized projects response (Nagata, 1993). Levy (2008) defines CALL as "discovering, finding and exploring computer applications for language teaching and learning" (p. 1). While Egbert expresses the CALL is "students learning language in any setting with, though, and around computer innovations" (2005, p.4). Beatty's (2003) definition states that CALL involves language learning "where students use computers and, as a result, improve their language" (p.7). Beatty (2003) recognizes that CALL covers the areas of "material design, technology, pedagogical theory, and teaching methods" (p. 8). Torat (2000) referenced that Computers can give a significance engaged, open learning condition, which fills the needs of informative language instructing.

Ahmad (1985) talks that the quick improvement of computer innovation in the late 1960s and early 1970s encouraged literary scholars and linguists to use computers which formed the basis for using computers to teach and learn languages. As a term, "CALL" was used in the 1980s replacing, previously introduced "CALI" (Computer Assisted Language Instruction), which was more teachers centered than students-centered. CALL then expanded its reach through the use of communicative approaches in a variety of new technologies. Now includes very interactive and communicative support for four language skills with the widespread use of internet resources and multimedia (Davies et al., 2012). In Pakistan, CALL has also been introduced quite a long time ago right after following grammar translation method and communicative approach. Still there is a lot to work on this approach to get desired results.

The use of CALL approach is highly achieving appreciation in teaching and learning foreign languages. Educational organizations have made great efforts to place computers for expanding the experience of imparting knowledge of language via adopting technology in teaching. As a result, the role of computers in learning and teaching and its effects in the classroom are widely explored (Chapelle, 2001, Dhaif, 1989, Galavis, 1998, Gruich, 2002, Hubbard, 1996, Kenning \& Kenning, 1983); Levy, 1997; Muir-Herzig, 2003; Pennington, 1996; Schofield, 1995). In this connection teaching any language computers are very much necessary in all the educational organizations in Pakistan.

According to Levy and Hubbard (2006) teachers should have the capability to get learning opportunities, environment and limitations of the classroom. Here teachers can be enabling to learn and understand information without having any interruption if they take regular training program in various fields of CALL which is 
fundamental for them to understand the updated teaching approaches and methods. The part of computers has increased so high over the past thirty years in the society and helped number of studies in exploring the potential of teaching tools. The existence of computers in all areas of human life is undeniable, and people have been innate to enjoy and appreciate learning with computers (Jalali \& Dousti, 2012).

Warchauer (1996) categorizes CALL into separate stages of development; Behavioral calls, communicative calls, integrative calls. This integrative CALL has two portions like, integration of (multimedia CD-ROM) and integration of (Internet). These phases sometimes have common characteristics because "the old is subsumed inside the new." In addition, each phase is used independently on the basis of preferences according to their application (Warchauer, 1996).

\section{Behavioristic Call}

Behavioristic theory was given by B.F.Skinner which influenced the principle stage of the behavioristic CALL. It was developed in 1960s and 70s following audio-linguistic approach to teach other language. By and large, behavioristic CALL lays on a certain supposition that language students can improve their learning when they step forward at their own momentum and have adequate time (Borras, 1998; Collis and Muir, 1984). Computers are knowledge producers whereas learners are receivers if computers are used in the language classrooms. All the CALL related technologies are the great sources of knowledge because all information stored in the hard copies are converted into soft copies. So, it is so easy for the students to receive knowledge by using computers, now laptops and mobile phone under the supervision of trained CALL teachers.

According to (Kern and Warschauer 2000, Taylor 1980, and Collis and Muir 1984) computers in teaching acted as a tutor and teaching machine. This means that the first few years of CALL include training applications and practices with separate grammar and vocabulary lessons. Using computer training, students can receive instant feedback based on their answers and work at their own pace inside and outside the classroom (Yulin Feng, 2012). The training of using computers in the field of teaching is extremely necessary in Pakistan although to some extent the computers and related technologies are in use.

\section{Communicative Call}

Cognitive-based communicative CALL was launched in the 1970s. Theories and pedagogies about language learning that are based on the theory of behaviorism are widely rejected, especially by linguist Noam Chomsky, writing review on behaviorism of BF Skinner. According to Chomsky, languages spoken by human are complicated to be learned fully. The reason is that children do not just copy or reproduce the language around and imitate like parrots. Moreover, children are capable enough to discover more about the language structures than the language they hear in their surroundings.

In the period of communicative CALL, various CALL programs have been developed to teach second and foreign languages. Warschauer (1996, p. 13) identified various computer roles and developed three CALL communicative models: (1) computers as teachers, (2) computers as encourager, and (3) computers as tool.

\section{- $\quad$ The first model as follows}

First, there are some practical skills training programs, but in a non-training format. Here computer play the role to know the correct reply therefore computer extended to be a model tutor. However, unlike drill and training programs, the procedure to find the right answer involves a relatively large selection of choices, controls, and student interactions. (Vol.5)

\section{- $\quad$ The second model is this}

An additional representation for communication activities is the computer as an incentive / stimulus. ... In that case, the rationale of the CALL activity is not to make students find the right answers, but to encourage for discussion, writing, or critical thinking among students. (Pages 5-6)

\section{- $\quad$ The third model is this}

Communicative CALL comes in the third model where computer is a tool.... In this role, the program does not have to provide language material, but allows students to use or understand language. (p. 6)

\section{Integrative Call}

The final phase, integrative CALL which was influenced by socio-cognitive linguistics by D. Hymes and M.A.K Halliday came into being in 1990s. They stressed that language grows basically through cognitive and social interactions (Kern \& Warschauer, 2000). By (Lightown and Spada 1999), people's knowledge or results can be raised to a higher level if they are in a rich and supportive environment. As a result, children are capable of learning their native language naturally without having intentional effort to learn or teach language when they are exposed to it. In this way, learning a native language and understanding its process of socialization with people play an important role for children.

Here two more innovations like multimedia and internet became the part of integrative CALL (Levy 2008). Multimedia presents the following kinds: video, images, animation, text, graphics and sound provided through 
computer (Hoogeveen 1995, Hu \& Deng 2007, Schmid 2008).

Hypermedia has started with multimedia resources that are not only text based, but also include two types of media such as text + sound or text + photos (Brett, 1995, Hu \& Deng, 2007). Students have mousses to click and keyboards to access many language assignments. There are many reasons why the use of Hypermedia is good for learning foreign languages: (1) Hypermedia is useful to facilitate authentic sample data for students (Akbulut 2007, Heller 1990, Wang 2006), (2) integration of four language skills (listening, speaking, reading, writing), (3) incorporation of bottom-up and top-down processing potentiality (Wang 2006), (4) the combination of text with multimedia and visual aid plus sound facility for reading comprehension (Akbulut 2007, Lomicka 1998) and (5) students, at their own path and pace, are capable to handle their learning (Akbulut 2007, AlKahtani 1999, Wang 2006). The mentioned above resources of hypermedia and multimedia are in use almost in every institution either of government or the private ones - but there is a need for them to include officially in our education system.

By using Internet, "students are able to find a great number of authentic data of their interest in a very short span of time like: articles from worldwide magazines and newspapers, radio programs, audio and videos, reviews on books and movies (Warschauer 1996 - P. 9). Nowadays, students have the access of internet since they are the end users of smart phones and laptops. What if the use of internet is made necessary in the classroom, our students and their learning will be channeled towards the positive and productive use of technology however they are wasting their time and money following the various social media and other sites.

\section{Research Methodology}

This study is based on survey research that is one of the basic tools of all outcomes through quantitative sort of research in studies. The quantitative survey is used to collect samples from the participants utilizing number of types like survey via online, online polls, questionnaires on paper and through web side surveys. The stress of quantitative methods is laid on the objective measurements and mathematical numerical or statistical data analysis through questionnaire or sometimes using computational techniques (Mark Balnaves and Peter Caputi, 2001). As mentioned above different ways of surveys to collect data, for this study paper questionnaire was given to the respondents to record their responses.

\section{Data Collection}

The survey questionnaire for the research study was designed having twenty-eight statements targeting the perceptions of the teachers covering different aspects of thinking as perceptions and approach for teaching using CALL in government colleges of Hyderabad. In this way, the first aspect of the questionnaire is to know the teachers' perception regarding the application of Computer Assisted Language Learning, second aspect is to investigate the hurdles to the implementation of CALL according to the teachers' perception and lastly to inquire about the strategies to include technological tool for teaching in Higher Secondary Courses.

The five-point Likert scale for the questionnaire was selected having points like strongly agree, agree, fairly agree, don't agree and strongly disagree. Later on, the entire collected data was analyzed through SPSS software. The questionnaire contains a brief explanation about the topic of thesis and definition of CALL for the participants understanding. The questionnaire was adopted from the studies of Yulin Feng who did his study on "Perceptions of English language Teachers' about Computer-Assisted Language Learning" and submitted at Texas A \& M University-Kingsville and Reza Dashtestani's work how did his research at University of Tehran, Iran on "Barriers to the implementation of CALL in EFL courses: Iranian EFL teachers' attitudes and perspectives".

The participants for this study were teachers of both genders' male and female but the female respondents were not equal to male because the female teaching staff available was less in number. Another reason was faced by the researcher that female teachers were found to be reluctant to show their willingness to be the part of this survey due to some ethical issues, not having permission from the principal of their respective college, and possibly they were insecure to give their personal information. As it is mentioned about the population for the study, the number of participants were sixty in total and in relevance to this, male respondents were thirty-six while twenty-four were female. Moreover, the participants who participated in this research survey they belong the colleges of Hyderabad Pakistan.

\section{Finding and Discussion}

The results are presented in frequency and percentage of gender like male and female who took part in the study. The percentage of the male in the study was $60 \%$ and frequency was $(n=36$ in number. But female staff who participated in study was $40 \%$ and in number they were $(n=24)$. The age of the participants taking part in the survey was $38.3 \%(n=23)$ between 35 to 40 years old, $31.7 \%(n=19)$ were 30 to 35 years old, and $23.3 \%(n=14)$ were of 40 to 45 years old, and $6.7 \%(n=4)$ were 25 to 30 years old. The next table was about the qualification of the teachers. The highest percentage of the teachers' qualification is $80 \%(n=48)$ that is Masters in English and 
$18.3 \%(\mathrm{n}-11)$ teachers are M.Phil. and only $1.7 \%(\mathrm{n}=01)$ were $\mathrm{PhD}$ degree holders who willingly participated. So far as the designation is concern, $78.3 \%(n=47)$ were serving as lecturer in their respective colleges and $20 \%$ $(n=12)$ teachers promoted to the post of Assistant Professor, lastly 1.7\% $(n=01)$ were Associate Professor working actively for long.

The result of the item, "CALL enhances students' motivation", was equal like $46.7 \%$ with two variables each like agree and strongly agree. And 4.4 is the mean score with $14.00 \%$ Co-efficient Variation. There is $86 \%$ reliability in the results. A large portion of the population which is $93 \%$ has shown its complete favor in the enhancement of motivation of students through CALL. However, $6.7 \%$ of the population is fairly agree that appears to be neutral. The feedback is quite similar for two variables like $45 \%$ participants agree and $43 \%$ strongly agree to the statement above however $86.3 \%$ agreement is found in total. The Mean score is 4.3 with $16.74 \%$ Co-efficient Variation for this statement. The reliability of this item is around $83 \%$ according to the replies collected from the participants. A little fluctuation is also observed in the collection of the response of "technology can be easily combined with English subject teaching" where 10.0\% population is found to be neutral. This seem to be that the participants are lacking exposer of the digital world even though living with gadgets all around them. It is contrary to the fact that $1.7 \%$ participants do not agree with statement above. The answers for this item recorded in four variables presented in the chart. The responses in agreement for the "willingness to learn how to use computer in teaching" is $93 \%$ in which $53.3 \%$ participants were strongly agree and $40 \%$ were agree. And the mean score is 4.4 and the Co-Efficient Variation is $15.33 \%$ which means that there is around $85 \%$ reliability was found there. Only $05 \%$ fairly agree and $1.7 \%$ disagree with the statement above.

$58.3 \%$ participants agree and along with strongly agree population is at $33.3 \%$. The Mean result of the statement, "CALL can be used to teach different subjects and their skills", is 4.2 securing $16.45 \%$ Co-efficient Variation. And the reliability is $84 \%$ for the use of CALL to teach other skills and subjects. Only 5.0\% participants are neutral and 3.3\% respondents do not agree. The results of $48.3 \%$ for agree and strongly agree stands with $26.7 \%$ and fairly agree population is $23.3 \%$. The total percentage of the agreement of the population is $75 \%$ with the statement which deals about "the easiness to learn how to work with computer for teachers". However, $1.7 \%$ disagreement was also observed in the data collection. The mean for this item is 4.0 while $18.97 \%$ is Co-Efficient Variation is $81 \%$ reliable. Here $60 \%$ participants agree that "CALL practice promotes teachers ' professional development" though $23.3 \%$ teachers strongly agree. In total $83.3 \%$ agreement also found. In the survey $11.7 \%$ participants responded to be neutral with the statement presented above and only $5.0 \%$ disagreed. The Mean is 4.0 while $18.69 \%$ is Co-Efficient Variation was found with $81 \%$ reliability result. The result shows $48.3 \%$ participants were agreeing and $26.7 \%$ were strongly agree about "the quality enhancement of the learning through CALL based teaching and learning". So, 75\% teachers showed interest in total and the fairly agree participants were $18.3 \%$. Merely, $5.0 \%$ got disagree and $1.7 \%$ teachers were strongly disagreed with the item above. The Mean is 3.9 along $23.09 \%$ Co-efficient Variation and $76 \%$ reliability was observed. The survey highlighted important aspect of the positive element that majority of the population is in favor that there ought to be "encouragement for the teachers to use technology in their class room while teaching lessons." $46.7 \%$ was for strongly agree while $43.3 \%$ was for agree. So, in total $90 \%$ agreement was found for the statement above. The fairly agree is $8.3 \%$ and only $1.7 \%$ population was found not to agree with the statement. The Mean score is 4.3 and the Co-Efficient Variation found to be $16.48 \%$ with $84 \%$ reliability. $87 \%$ respondents were in the favor that "variety comes in teaching of other courses using technology". And 1.7\% participants showed disagreement with the item. The Mean score is 4.1 and then $15.85 \%$ Co-efficient Variation with $84 \%$ reliability. The top most value is $55.0 \%$ where population agreed to the statement that "technology facilitates the process of teaching" and 30\% strongly agree too. Only 9\% teachers were found neutral. The Mean score is 4.1 and the Co-Efficient Variation is $16.08 \%$ with $84 \%$ reliability of the survey. As far as "the assessment of the students for their work and the proper feedback via computer help" is concern, 71\% participants agreed in total. Only $15 \%$ appears to be neutral but only $3.3 \%$ teachers do not agree with the statement above. The Mean score is 3.8 and $20 \%$ Co-Efficient Variation observed $80 \%$ reliability. The result of $75 \%$ responses is in the agreement that "CALL helps in the target language teaching and learning". $45 \%$ teachers agree and 30\% strongly agree with the item presented above. $23.3 \%$ are fairly agree but only $1.7 \%$ population do not agree with the statement.

The data in the second slot given shows perception concerning the obstacles to the implementation of CALL in Higher Secondary courses. The insight of the teachers, serving as Lecturers, Assistant Professors and Associate Professors in the government colleges, was observed regarding the hurdles in the implementation of CALL in Higher Secondary course. The data in the chart represents the responses of the population who took part in the survey. A bit more than $60 \%$ participants were agreed and $35 \%$ and $26.7 \%$ were strongly agreed. According to them "it is difficult to implement CALL in Higher Secondary classes". About 21.7\% agreeing partially being unbiased and lastly $16.7 \%$ do not agree with the statement. Despite this, the Mean score is 3.7 and the Co-Efficient Variation is $28.18 \%$. The highest frequency is found like 21 and $35.0 \%$ participants agreed and $25.0 \%$ teachers strongly agreed. So, in total $60 \%$ teachers were on agreement accepting that "it is problematic for them to generate materials based on computer". $20 \%$ participants were fairly agreeing but $20 \%$ population 
appeared to disagreement. Moreover, the Mean score is 3.6 and $30.67 \%$ is the Co-Efficient Variation. Almost 93.4\% participants agreed with that "computer assisted language learning training programs are not sufficient to train teaching staff". In this way $56.7 \%$ teachers strongly agreed and $36.7 \%$ agreed to statement above. Only $6.7 \%$ participants were fairly agreed. However, the Mean score of this item is 4.5 and Co-Efficient Variation is $13.87 \%$. The significant of "teachers' technological literacy is low enough to implement CALL" as tool. In this regard, 40\% teachers agreed and 35\% strongly agreed. Moreover, 21.7\% participant moderately agreed. Only $3.3 \%$ teachers did not agree with statement above. The Mean score is 4.0 and the Co-Efficient Variation appeared to be $20.68 \%$. The result of $90 \%$ participants showed their agreement to the statement which highlights that "there is deficiency of facilities in Higher Secondary text books based on CALL". According to the data only $10 \%$ teachers showed their uncertainty for the statement above. Here the Mean score for this is $4.3 \%$ and CoEfficient Variation is $15.49 \%$ for this statement. The highest percentage is 26.7 of those teachers who do not agree with the statement that the use of "technology may distract the learners rather than providing them an aid". And the strongly disagreed were $15 \%$ so in total it was $41.7 \%$. But surprisingly the agreement is same as $41.7 \%$ in total. Meanwhile, $16.7 \%$ were fairly agreed. The Mean score is $3.0 \%$ along $44.88 \%$ Co-efficient Variation. The result showed 50\% participants were agreeing and strongly agreeing in the favor of statement which is about "injustice due to the use of CALL in education because some of the students are more familiar with technological gadgets". And $28.3 \%$ were agreeing fairly. But $21.6 \%$ disagreement is also present in the chart. The Mean score is 3.4 and the Co-Efficient Variation is $31.20 \%$. The result of $40 \%$ participants were in disagreement with the statement that "it is time and energy consuming if computers are used in the class room" but $33 \%$ participants agreed. However, $26.7 \%$ population was fairly agreed. The Mean score was 3.0 and $40.18 \%$ Co-Efficient Variation was observed too. The responses of $78.4 \%$ were agreeing and strongly agreeing but only $5 \%$ participants were disagreeing statement above. However, $16.7 \%$ teachers were fairly agreeing with the statement that "there is a lack of attention of educational course designers and supervisors to include CALL in English text books". The Mean score was 4.0 and the Co-Efficient Variation was $22.05 \%$. So, $78 \%$ result was reliable in the survey. $53.3 \%$ teachers showed their interest with the statement that "the teachers and learners of the college to be technophobic and anxious to use technology". Only 3.3\% responses were strongly disagreed. The Mean score was 3.4 and Co-Efficient Variation is $35.29 \%$. The third section of the survey is about the perception of the strategies regarding the inclusion of the technologies in education. The data collected in the form of Mean and Std, Deviation along with the Co-Efficient Variation. The understanding of the teachers, serving in government colleges of the Hyderabad Pakistan.

The third section of the survey is about the perception of the strategies regarding the inclusion of the technologies in education. The data collected in the form of Mean and Std, Deviation along with the Co-Efficient Variation of every item presented in the questionnaire. The understanding of the teachers who are serving in government colleges of the Hyderabad division as Lecturer, Assistant Professors and Associate Professors was recorded through the statements given in the questionnaire. The participant's response was $98.4 \%$ for the statement which is about teachers' knowledge update for new software periodically related to CALL. The Mean score was 4.4 with Co-Efficient Variation of $12.14 \%$ so around $88 \%$ replies are reliable in the survey. The result based on the responses was in the favor of strongly agreeing as 50\% and $46.7 \%$ were agreeing with the statement that "the invitation of teachers to work for materials based on computer assisted language learning". The Mean score is 4.4 and the Co-Efficient Variation is $12.87 \%$. The result in total $93.3 \%$ was in agreement for the statement that "the facilitation and implementation of CALL for teachers". The Mean score is 4.4 with $16.84 \%$ Co-Efficient Variation.

The participants showed their keen interest in "workshops and meetings on CALL implementation in Higher Secondary course". Therefore, the $98.3 \%$ participants were agreed to the statement. The Mean score is 4.4 and $15.29 \%$ Co-Efficient Variation. The $48.3 \%$ respondents were strongly agreed and $41.7 \%$ agreed that there ought to be "programs and sessions for awareness on the use and benefits of CALL". 4.3 is the Mean score and $15.49 \%$ Co-Efficient Variation was observed while collecting data. The responses from the participants were in agreement in $91.7 \%$ for the statement that "funding teachers to purchase the necessary software to be used in text books" which is further separated as $46.7 \%$ strongly agree and $45 \%$ agree. The Mean of this statement is 4.3 and $17.56 \%$ is the Co-Efficient Variation which mean again with large ratio of $82.44 \%$ the researcher found the reliability for this last item.

\section{Results}

The descriptive analysis outcome exposed that almost all the respondents recorded their answers positively with in five variables while the mean score for majority of the items were between agreeing and strongly agreeing. Additionally, the results in Table 2 shows the highest Mean score $(n=60, M=4.4$, Std Dev $=.67460)$ having $15.33 \%$ Co-efficient Variation for statement \# 2.03 (I am willing to learn how to use computers in teaching) along with two closest Mean Scores with minor fluctuations like ( $\mathrm{n}=60, \mathrm{M}=4.4$, Std Dev = .61617) having $14.00 \%$ Co-efficient Variation for statement \# 2.01 (CALL enhances students' motivation) and ( $\mathrm{n}=60, \mathrm{M}=4.3$, 
Std Dev $=.70890$ ) having $16.48 \%$ Co-efficient Variation for statement \# 2.8 (Teachers should be encouraged to use technology in their class) whereas the lowest Mean score $(\mathrm{n}=60$, Mean $=3.8$, Std Dev $=.76117)$ having 20.03\% Co-efficient Variation for statement \# 2.11 (Computers help teachers to assess students and provide appropriate feedback).

Likewise, the results of Table 3 for the perceptions of the obstacles to the implementation of CALL in Higher Secondary course were revealed like the top most Mean score $(n=60$, M 45, Std Dev $=.62436)$ with $13.87 \%$ Co-efficient Variation for the survey item \# 3.15 ( There is a lack of CALL education in teachers training programs) was detected besides the Mean score at the lowest level $(\mathrm{n}=60, \mathrm{M}=3.0667$, Std Dev $=1.20)$ along 40\% Co-efficient Variation for item \# 3.20 (Using computers in Higher Secondary courses is energy-andtime consuming).

In the same manner, finally the Table 4 was to inquire about the perceptions of the strategies in include communication technology and the highest Mean score for items 23 to 26 is the same with tiniest ups and downs $(\mathrm{n}=60, \mathrm{M}=4.4500,4.4667,4.4000,4.4333, \mathrm{Std} \mathrm{Dev}=.53441, .56648 .74105 .67313)$ was received for (updating teachers CALL knowledge, inviting teachers to cooperate in CALL projects, providing teachers CALL facilities and attending workshops related to $C A L L)$, and the lowest Mean score is $(\mathrm{n}=60, \mathrm{M}=4.3$, Std Dev $=.66617$ and .75521) with Co-efficient Variation up to 17.56\%. for item \# 27 and 28 like (The programs and sessions for the sake of awareness on the uses and benefits of CALL) and (Some software to be purchased for using teaching text books if teacher funded).

\section{Conclusion}

After doing research on the respective topic, the study explores through investigating about the barriers in the path of education for implementing technological tool like CALL (computer assisted language learning) in the government institutions for Higher Secondary Education in Hyderabad. In this regard, the researcher tried best to attain insights of the teachers so far as the inclusion of technology is concern. Moreover, the data received for the research objectives as: "to know the present condition of the use and application of CALL in Government Colleges, to check into thoroughly about the perceptions of teachers regarding strategies ought to be adopted to include CALL, and to inquire about the main obstacles to the implementations of CALL in Government colleges via teachers' perceptions was analyzed.

In order to get the outcomes from the questionnaire by assessing observation of CALL application, the majority of the teachers declared the use of computer and related technology is surly helpful for both learners and teacher. Moreover, participants also responded that with the help of CALL quality of teaching and learning enhances for sure. The participants also agreed that the use of computer and relevant gadgets are supportive to assess students and give them appropriate feedback in the arena of teaching language. Furthermore, it was reported that CALL practice facilitates to bring variety not only in teaching English language but other courses as well.

According to the responses of the table 3, the government teachers practicing teaching in colleges strongly agree on the compulsions of CALL implementation like not having enough technological resources, lack of computers, and lack of CALL education in teachers training programs. Another absence is the proper attention from the course designers towards adding CALL in English text books. Despite this, the participants also strongly disagree with idea that technology may create distraction rather than support for learner. Similarly, the cultural resistance and the injustice using computers were other sorts of issues too observed through questionnaire. In contrast with the discussion above about the hurdles to the implementation of CALL in Higher Secondary Education, some the teachers of the point that students including teachers supposed to be technophobic and anxious to use technological tools or devices while teaching in class.

The third section of the questionnaire presented in the Table 4 focusing on the perceptions of the teachers about the strategies to include technology in education of HSE level. The overall impression of the participants was that they were interested to attend some sort of training to use CALL to understand themselves the benefits of computer assisted language learning though most of the teachers are aware of using technology in the form of Cell phone and internet and quite capable to use various applications available of their interest. Although it is the routine to use mobile, internet for entertainment or some productive work and social networking tools, the participants in the specific arena of education need some input to be professional. In addition to this the teachers are of the opinion in the favor of funding teachers or buy them some mandatory software to utilize with the text book.

\section{References}

Afshari, M., Ghavifekr, S., Siraj, S., \& Jing, D. (2013). Students' Attitudes towards Computer-assisted Language Learning. Procedia - Social and Behavioral Sciences, 103, 852-859.

Al-Awidi, H.M., \& Ismail, S.A. (2014). Teachers' Perceptions of the Use of Computer Assisted Language Learning to Develop Children's Reading Skills in English as a Second Language in the United Arab 
Emirates. Early Childhood Education Journal, 42, 29-37.

Ashraf, M. (2016). The effectiveness of integrating computer assisted language learning (CALL) into the textbook based syllabus of English language: teachers' and learners' perspectives.

Basal, A. (2015). Perceptions of Pre-service English Teachers towards the Integration of an LMS into English Language Teacher Education. The Journal of Technology and Teacher Education, 23, 485-507.

Baskaran, L., \& Shafeeq, C. (2015). ESL Teachers' Perception of CALL Integration in ELT. International Journal on Studies in English Language and Literature (IJSELL), 3(5), 63-74.

Bhatti, T. (2013). Teaching Reading through Computer-Assisted Language Learning.

Dashtestani, R. (2012). Barriers to the implementation of CALL in EFL courses: Iranian EFL teachers' attitudes and perspectives. The jalt call Journal, 8(2), 55-70.

Dashtestani, R. (2014). Computer literacy of Iranian teachers of English as a foreign language: Challenges and obstacles. International Journal of Pedagogies and Learning, 9, 100 - 87.

Farhat, P.A., \& Dzakiria, H. (2017). Pronunciation Barriers and Computer Assisted Language Learning (CALL): Coping the Demands of 21st Century in Second Language Learning Classroom in Pakistan. International Journal of Research, 2, 53-62.

Hani, N. A. B. (2014). Benefits and barriers of computer assisted language learning and teaching in the Arab world: Jordan as a model. Theory and Practice in Language Studies, 4(8), 1609.

Hussain, S. (2014). Attitudes of English language learners towards computer assisted language learning in Karachi.

Irshad, S., \& Ghani, M. (2015). Benefits of CALL in ESL Pedagogy in Pakistan: A Case Study.

Jamil, M. (2012). Perceptions of University Students regarding Computer Assisted Assessment. Turkish Online Journal of Educational Technology, 11, 267-277.

Khodabandelou, R., That, J.E., MelindaAnne, A., S.Selvaraju, P., Ken, T.Y., Kewen, Z., Yan, Z., \& Ning, T. (2016). Exploring the Main Barriers of Technology Integration in the English Language Teaching Classroom: A Qualitative Study. International Journal of Education and Literacy Studies, 4, 53-58.

Kim, H.K. (2008). Beyond Motivation: ESL/EFL Teachers' Perceptions of the Role of Computers. the CALICO Journal, 25, 241-259.

Nadeem, M., Mohsin, M. N., Mohsin, M. S., \& Hussain, K. H. (2012). Use of computer assisted language learning in improving pronunciation among prospective teachers.

Nila, N. (2013). Implementation of CALL in the EFL classroom: teachers' perspective and attitudes in developing CALL-based classroom.

Önsoy, S. (2004). Students' and teachers' attitudes towards the use of computer-assisted language learning at the Preparatory School of Celal Bayar University.

Özturk, N. (2013). Using CALL in Language Teaching and Learning, in consideration of its Strengths and Limitations.

Raman, K., \& Yamat, H. (2014). Barriers Teachers Face in Integrating ICT during English Lessons: A Case Study. Malaysian Online Journal of Educational Technology, 2(3), 11-19.

Samadi, F., Maghsoudi, M., \& Azizmohammadi, F. (2014). The Impact of CALL Technology on Improving Iranian Female Highschool Students' Speaking Ability. Procedia - Social and Behavioral Sciences, 98, $1666-1671$. 